\title{
DVP Regmen
}

National Cancer Institute

\section{Source}

National Cancer Institute. DVP Regmen. NCI Thesaurus. Code C9656.

A chemotherapy regimen consisting of daunorubicin, prednisone and vincristine that may be used as remission induction in patients with relapsed acute lymphoblastic leukemia (ALL). 